\title{
A Simple Molecular Machine Operated by Photoinduced Proton Transfer
}

Serena Silvi, Arturo Arduini, Andrea Pochini, Andrea Secchi, Massimiliano Tomasulo, Françisco M. Raymo, Massimo Baroncini and Alberto Credi*

Dipartimento di Chimica “G. Ciamician”, Università di Bologna, via Selmi 2, 40126 Bologna, Italy, Dipartimento di Chimica Organica e Industriale, Università di Parma, via Usberti 17/a, 43100 Parma, Italy, and Center for Supramolecular Science, Department of Chemistry, University of Miami, 1301 Memorial Drive, Coral Gables, FL 33146-0431

E-mail: alberto.credi@unibo.it

\section{Supporting Information}




\section{Experimental Methods}

Materials. Tributylamine $\left(\mathrm{Bu}_{3} \mathrm{~N}\right.$, Fluka, $\left.\geq 99.5 \%\right)$ and trifluoromethanesulfonic acid $\left(\mathrm{CF}_{3} \mathrm{SO}_{3} \mathrm{H}\right.$, Fluka, $>99 \%$ ) were used as received. The solvents dichloromethane and acetonitrile for spectroscopic experiments were purchased from Merck (Uvasol ${ }^{\mathrm{TM}}$ ) and used without further purification. The solvent dichloromethane for electrochemical experiments was purchased from Romil (Hi-Dry ${ }^{\mathrm{TM}}$ ) and used without further purification. SP and the bromide salt of $\mathbf{A}^{+}$were prepared according to literature procedures. ${ }^{\mathrm{S} 1, \mathrm{~S} 2}$ Tris(N-phenylureido)calix[6] arene wheel $\mathbf{C}$ was synthesized as described previously. ${ }^{\mathrm{S} 3}$

Absorption Spectra. The absorption spectra were recorded with a Perkin Elmer $\lambda 40$ spectrophotometer, on air equilibrated dichloromethane (Merck Uvasol' ${ }^{\mathrm{TM}}$ ) solutions at room temperature (ca. $298 \mathrm{~K}$ ), with concentrations ranging from $1 \times 10^{-5}$ to $1 \times 10^{-4} \mathrm{~mol} \mathrm{~L}^{-1}$. Solutions were examined in 1-cm spectrofluorimetric quartz cells. The experimental error on the wavelength values was estimated to be $\pm 1 \mathrm{~nm}$.

Titration experiments. Titration of $\mathbf{A}^{+}$with acid was performed by adding small aliquots (typically $2 \mu \mathrm{L})$ of a concentrated $\left(1.2 \times 10^{-3} \mathrm{M}\right)$ solution of $\mathrm{CF}_{3} \mathrm{SO}_{3} \mathrm{H}$ in $\mathrm{CH}_{3} \mathrm{CN}$ to $2.5 \mathrm{~mL}$ of a dilute $\left(4.8 \times 10^{-5} \mathrm{M}\right)$ solution of $\mathbf{A}^{+}$by using a microsyringe. Titration of $\mathbf{C}$ with $\mathbf{A} \mathbf{H}^{2+}$ was performed by adding small aliquots (typically $10 \mu \mathrm{L})$ of a concentrated $\left(1.1 \times 10^{-3} \mathrm{M}\right)$ solution of $\mathrm{AH}^{2+}$ to $2 \mathrm{~mL}$ of a dilute $\left(5.8 \times 10^{-5} \mathrm{M}\right)$ solution of $\mathbf{C}$ by using a microsyringe. UV/Vis absorption changes were monitored during the titration. The data were treated according to the formation of a 1:1 complex by means of the SPECFIT software. ${ }^{\mathrm{S} 4}$ 
Irradiation Experiments. Irradiation was performed with a 150-W tungsten-halogen lamp, using a $455 \mathrm{~nm}$ cut-off filter. The solution was maintained under stirring during the irradiation time.

Electrochemical measurements. Cyclic voltammetric (CV) and differential pulse voltammetric (DPV) experiments were carried out in argon-purged $\mathrm{CH}_{2} \mathrm{Cl}_{2}$ (Romil Hi-Dry ${ }^{\mathrm{TM}}$ ) with an Autolab 30 multipurpose instrument interfaced to a PC. The working electrode was a glassy carbon electrode (Amel; $0.07 \mathrm{~cm}^{2}$ ); its surface was routinely polished with a $0.3 \mu \mathrm{m}$ alumina-water slurry on a felt surface, immediately prior to use. In all cases, the counter electrode was a Pt wire, separated from the solution by a frit; an Ag wire was employed as a quasi-reference electrode, and ferrocene was present as an internal standard. The concentration of the compounds examined was $9 \times 10^{-4} \mathrm{M}$; tetrabutylammonium hexafluorophosphate $9 \times 10^{-2} \mathrm{M}$ was added as supporting electrolyte. Cyclic voltammograms were obtained at sweep rates varying from 0.02 to $5 \mathrm{~V} \mathrm{~s}^{-1}$. The IR compensation implemented within the Autolab 30 was used, and every effort was made throughout the experiments in order to minimize the resistance of the solution. In any instance, the full electrochemical reversibility of the voltammetric wave of ferrocene was taken as an indicator of the absence of uncompensated resistance effects. 


\section{Synthesis and characterization}

1-Decyl-4,4'-Pyridylpyridinium Hexafluorophosphate $\left(\mathbf{A} \cdot \mathrm{PF}_{6}\right)$. A saturated aqueous solution of ammonium hexafluorophosphate was added to a solution of the bromide salt of $\mathbf{A}^{+}$( $250 \mathrm{mg}, 0.7$ mmol) in acetone $(17 \mathrm{~mL})$. The mixture was stirred at ambient temperature for $15 \mathrm{~min}$ and concentrated under reduced pressure. The resulting precipitate was filtered off and washed with water $(5 \times 10 \mathrm{~mL})$ to yield the hexafluorophosphate salt of $\mathbf{A}^{+}(224 \mathrm{mg}, 72 \%)$ as a white solid. FABMS: $m / z=297\left[\mathrm{M}-\mathrm{PF}_{6}\right]^{+} ;{ }^{1} \mathrm{H}-\mathrm{NMR}\left(300 \mathrm{MHz}, \mathrm{CDCl}_{3}\right): \delta=0.89(3 \mathrm{H}, \mathrm{t}, 7 \mathrm{~Hz}), 1.21-1.34$ (10H, m), 1.34-1.47 (4H, m), 1.99-2.09 (2H, m), 4.69 (2H, t, 7 Hz), 7.99-8.01 (2H, m), 8.52 $(2 \mathrm{H}, \mathrm{d}, 6 \mathrm{~Hz}), 8.83(2 \mathrm{H}, \mathrm{d}, 6 \mathrm{~Hz}), 9.13(2 \mathrm{H}, \mathrm{d}, 6 \mathrm{~Hz}) ;{ }^{13} \mathrm{C}-\mathrm{NMR}\left(100 \mathrm{MHz}, \mathrm{CD}_{3} \mathrm{OD}\right): \delta=14.5$, $23.8,27.3,30.2,30.5,30.6,30.7,32.6,33.1,63.0,123.7,127.3,143.9,146.6,151.9,155.3$.

\section{Results and discussion}

Formation of the $[\mathbf{C} \cdot \mathbf{A H}]^{2+}$ pseudorotaxane. Figure S1 shows that the thread-like compound $\mathbf{A}^{+}$can be converted into the protonated species $\mathrm{AH}^{+}$by adding a stoichiometric amount of triflic acid in $\mathrm{CH}_{2} \mathrm{Cl}_{2}$. 


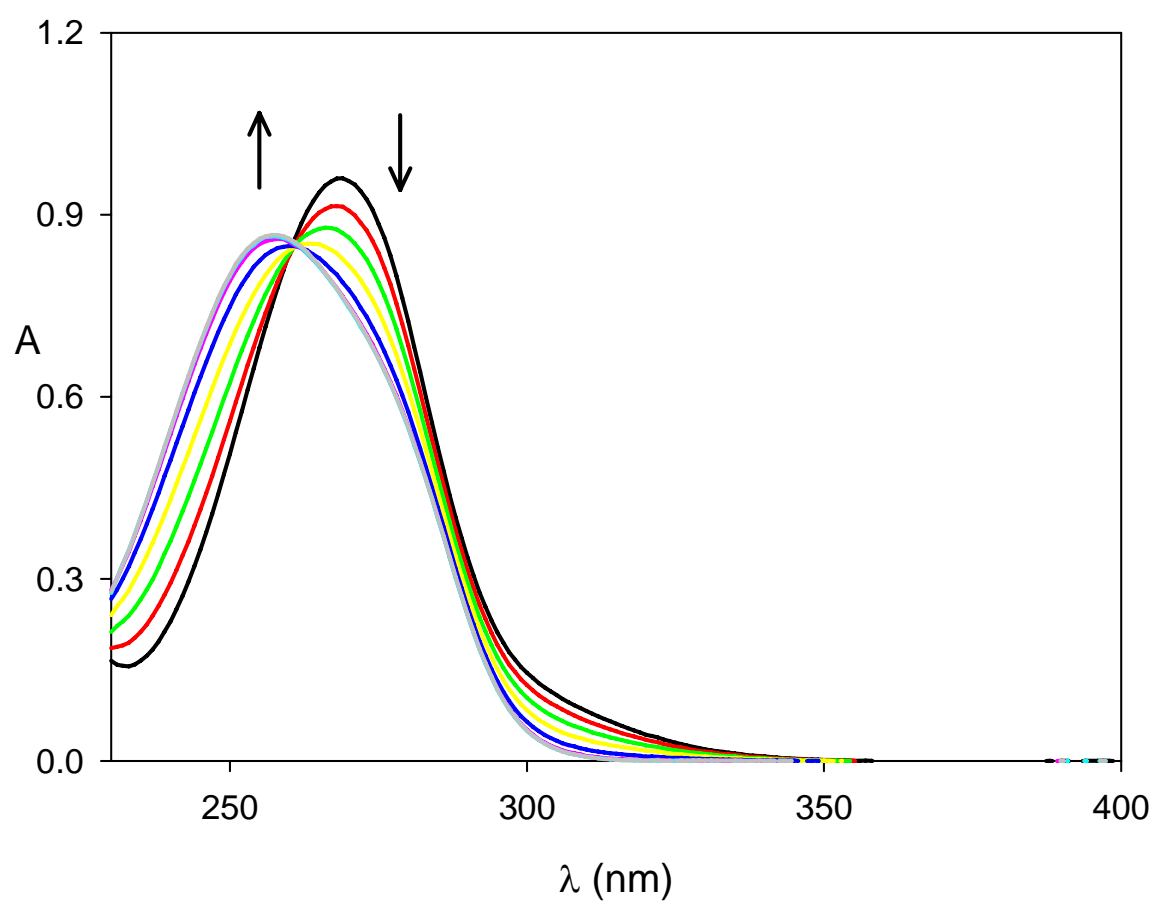

Figure S1. Absorption changes upon titration of a $4.8 \times 10^{-5} \mathrm{M}$ solution of $\mathbf{A}^{+}$with $\mathrm{CF}_{3} \mathrm{SO}_{3} \mathrm{H}$ up to 1.0 equivalents $\left(\mathrm{CH}_{2} \mathrm{Cl}_{2}, \mathrm{RT}\right)$.

A comparison of the absorption spectrum of a 1:1 mixture of the thread-like species $\mathrm{AH}^{2+}$ and calixarene $\mathbf{C}$ with the sum of the spectra of the individual components (Figure S2) shows that they interact electronically. In particular, a charge-transfer band is observed in the visible region $\left(\lambda_{\max }=478 \mathrm{~nm}, \varepsilon=500 \mathrm{M}^{-1} \mathrm{~cm}^{-1}\right)$, where none of the isolated molecular components exhibit absorption features. These observations suggest that in $\mathrm{CH}_{2} \mathrm{Cl}_{2}$ wheel $\mathbf{C}$ and thread $\mathrm{AH}^{2+}$ form a very stable ( $K=6 \pm 2 \times 10^{6} \mathrm{M}^{-1}$ from spectrophotometric titrations) pseudorotaxane-type complex. 


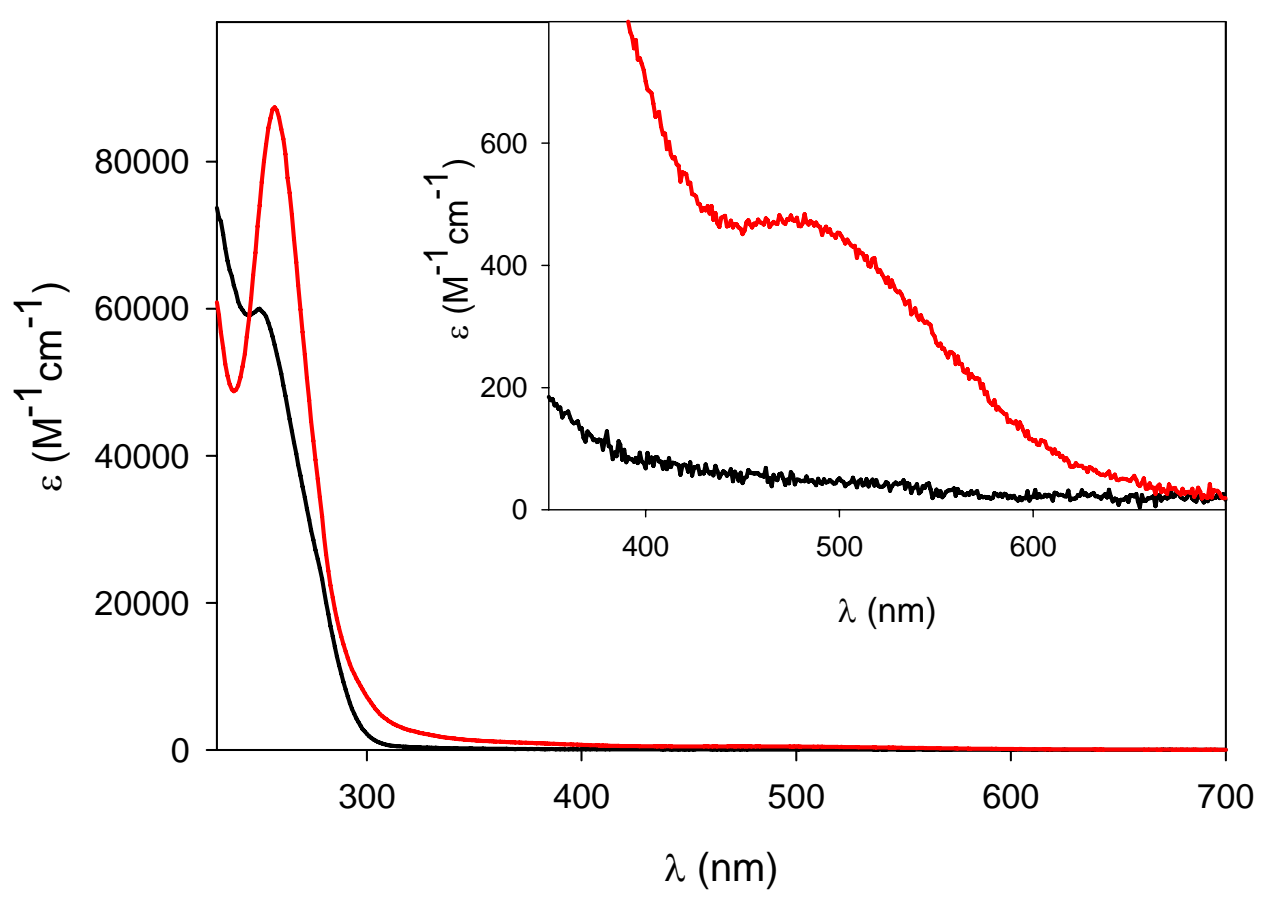

Figure S2. Sum of the spectra of the separated components $\mathbf{A}^{+}$and $\mathbf{C}$ (black line) compared with the absorption spectrum of a 1:1 mixture of $\mathbf{A H}^{2+}$ and $\mathbf{C}$ (red line) $\left(\mathrm{CH}_{2} \mathrm{Cl}_{2}, \mathrm{RT}\right)$. Upon titration of a $5.8 \times 10^{-5} \mathrm{M}$ solution of $\mathbf{C}$ with $\mathrm{AH}^{2+}$ an association constant of $6 \pm 2 \times 10^{6} \mathrm{M}^{-1}$ was determined.

In contrast, the absorption spectrum of a 1:1 mixture of the non-protonated thread $\mathbf{A}^{+}$and $\mathbf{C}$ is identical to the sum of the spectra of the individual components, indicating the absence of interactions between them in our conditions. Should a $[\mathbf{C} \cdot \mathbf{A}]^{+}$complex be formed, it must have a stability constant smaller than $10^{4} \mathrm{M}^{-1}$.

Voltammetric experiments confirm the above observations. Thread $\mathbf{A}^{+}$shows two reduction processes (Figure S3, blue line): the first one is reversible $\left(E_{1 / 2}{ }^{\prime}=-0.90 \mathrm{~V}\right.$ vs SCE), while the second one is irreversible ( $E^{\prime \prime}=-1.57 \mathrm{~V}$ vs SCE, from DPV experiments). The electrochemical behavior of $\mathbf{A}^{+}$is practically not affected by the presence of 1 equivalent of $\mathbf{C}$ (Figure S3, black 
line), indicating that the interactions between these species are negligible in our conditions. Thread $\mathrm{AH}^{2+}$ shows two reversible reduction waves (Figure S3, red line; $E_{1 / 2}{ }^{\prime}=-0.28 \mathrm{~V}, E_{1 / 2}{ }^{\prime \prime}=$ $-0.80 \mathrm{~V}$ vs SCE), indicative of its pseudo-viologen nature. In presence of 1 equivalent of $\mathbf{C}$ (Figure S3, green line) the first reduction potential undergoes a large negative shift and becomes poorly reversible $\left(E^{\prime}=-0.44 \mathrm{~V}\right.$ vs SCE, from DPV experiments): in other words, the axle becomes more difficult to reduce, reflecting the stabilization offered by the wheel. The second reduction process of $\mathbf{A H}^{2+}$ in presence of 1 equivalent of $\mathbf{C}$ occurs at the same potential as for the free axle, indicating that one-electron reduction of $\mathrm{AH}^{2+}$ promotes its dethreading from $\mathbf{C}$. These results are in agreement with those observed for a pseudorotaxane composed of wheel $\mathbf{C}$ and $1,1^{\prime}$-dioctyl-4,4'-bipyridinium as the axle. ${ }^{\mathrm{S} 5}$

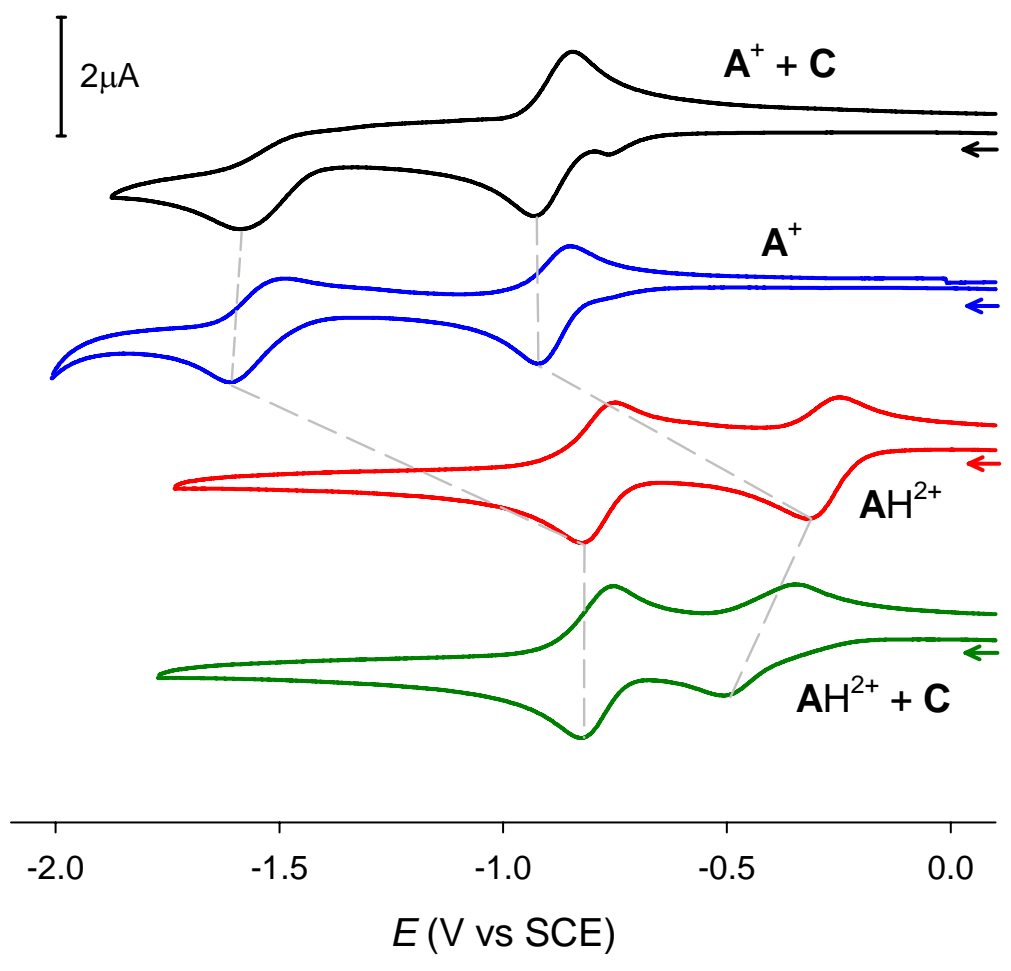

Figure S3. Cyclic voltammetric curves $\left(9 \times 10^{-4} \mathrm{M} \mathrm{CH}_{2} \mathrm{Cl}_{2}\right.$ solution, $9 \times 10^{-2} \mathrm{M} \mathrm{TBAPF}_{6}, 293 \mathrm{~K}$; scan rate: $\left.0.2 \mathrm{~V} \mathrm{~s}^{-1}\right)$ on reduction of $\mathbf{A}^{+}$alone (blue line) and with 1 equivalent of $\mathbf{C}$ (black line), and of $\mathbf{A} \mathbf{H}^{2+}$ alone (red line) and with 1 equivalent of $\mathbf{C}$ (green line). 
Control experiments for dark proton exchange. We performed some control experiments, in the same conditions of the proton exchange experiments, but in the absence of acid, in order to verify the stability of the system and look for possible interactions between the various components.

A dichloromethane solution of SP $\left(4.8 \times 10^{-5} \mathrm{M}\right)$ left in the dark at room temperature, is stable in time for several days as indicated by its absorption spectrum. Specifically, no evidence for formation of $\mathbf{M E}$ or $\mathbf{M E H}^{+}$was found.

The absorption spectrum of a dichloromethane solution of $\mathbf{S P}$ and $\mathbf{A}^{+}$(both $4.8 \times 10^{-5} \mathrm{M}$ ) is identical to the sum of the spectra of the individual species. Such a solution is stable in the dark at room temperature for several days. Specifically, the absorption spectrum shows that neither ME nor $\mathbf{M E H}^{+}$are formed in these conditions.

The absorption spectrum of a dichloromethane solution of $\mathbf{S P}, \mathbf{A}^{+}$and $\mathbf{C}\left(\right.$ all $\left.4.8 \times 10^{-5} \mathrm{M}\right)$ is identical to the sum of the spectra of the individual species. Such a solution is stable in the dark at room temperature for several days. Specifically, the absorption spectrum shows no evidence for formation of either $\mathbf{M E}, \mathbf{M E H}^{+}$or the pseudorotaxane $[\mathbf{C} \cdot \mathbf{A H}]^{2+}$ in these conditions.

Proton exchange in the $\mathbf{S P}-\mathrm{AH}^{2+}$ system. The absorption spectrum of a $\mathrm{CH}_{2} \mathrm{Cl}_{2}$ solution containing $\mathrm{AH}^{2+}$ (obtained by addition of 1 equiv of $\mathrm{CF}_{3} \mathrm{SO}_{3} \mathrm{H}$ to $\mathbf{A}^{+}$) immediately after the addition of 1 equiv of SP evidences no interactions between the two compounds. By keeping the solution in the dark, spectral changes consistent with the formation of $\mathbf{M E H}^{+}$are observed, indicating that a proton exchange from $\mathbf{A H}^{2+}$ to $\mathbf{S P}$ takes place (Figure S4). When the equilibration is completed (after 7 days in our conditions) about $90 \%$ of SP has been converted to $\mathrm{MEH}^{+}$. 


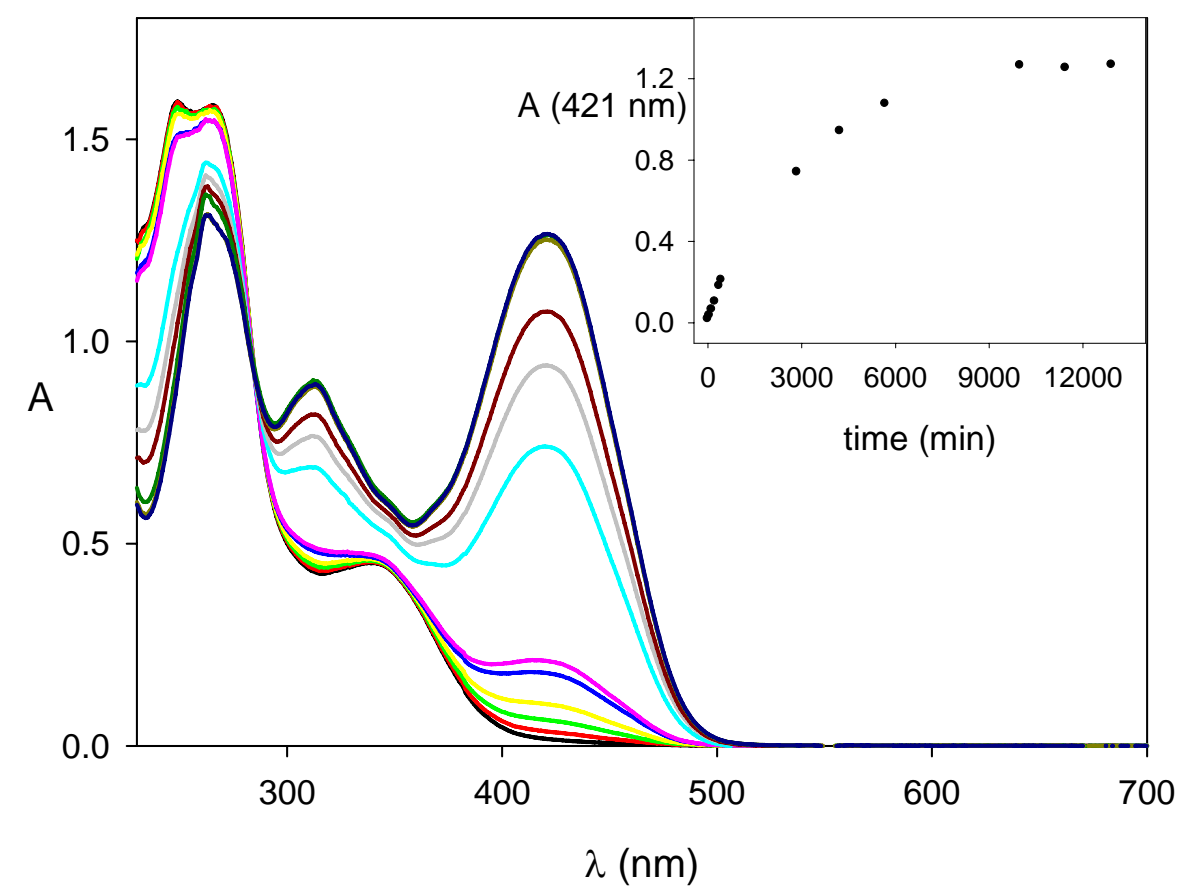

Figure S4. Absorption changes after addition of 1 equivalent of SP to a $4.8 \times 10^{-5} \mathrm{M}$ solution of $\mathbf{A H}^{2+}\left(\mathrm{CH}_{2} \mathrm{Cl}_{2}\right.$, RT). The inset shows the absorption changes at $421 \mathrm{~nm}$ vs. time.

By irradiating the equilibrated solution, containing mainly $\mathbf{A}^{+}$and $\mathbf{M E H}^{+}$, with visible light $(\lambda>450 \mathrm{~nm})$ the initial absorption spectrum is obtained, showing that a proton has been transferred from $\mathbf{M E H}{ }^{+}$to $\mathbf{A}^{+}$, giving back the starting $\mathbf{A H}{ }^{2+}$-SP state (Figure S5). The proton transfer process is reversible and thermal equilibration-light irradiation cycles can be repeated on the same solution without loss of signal (Figure S6). 


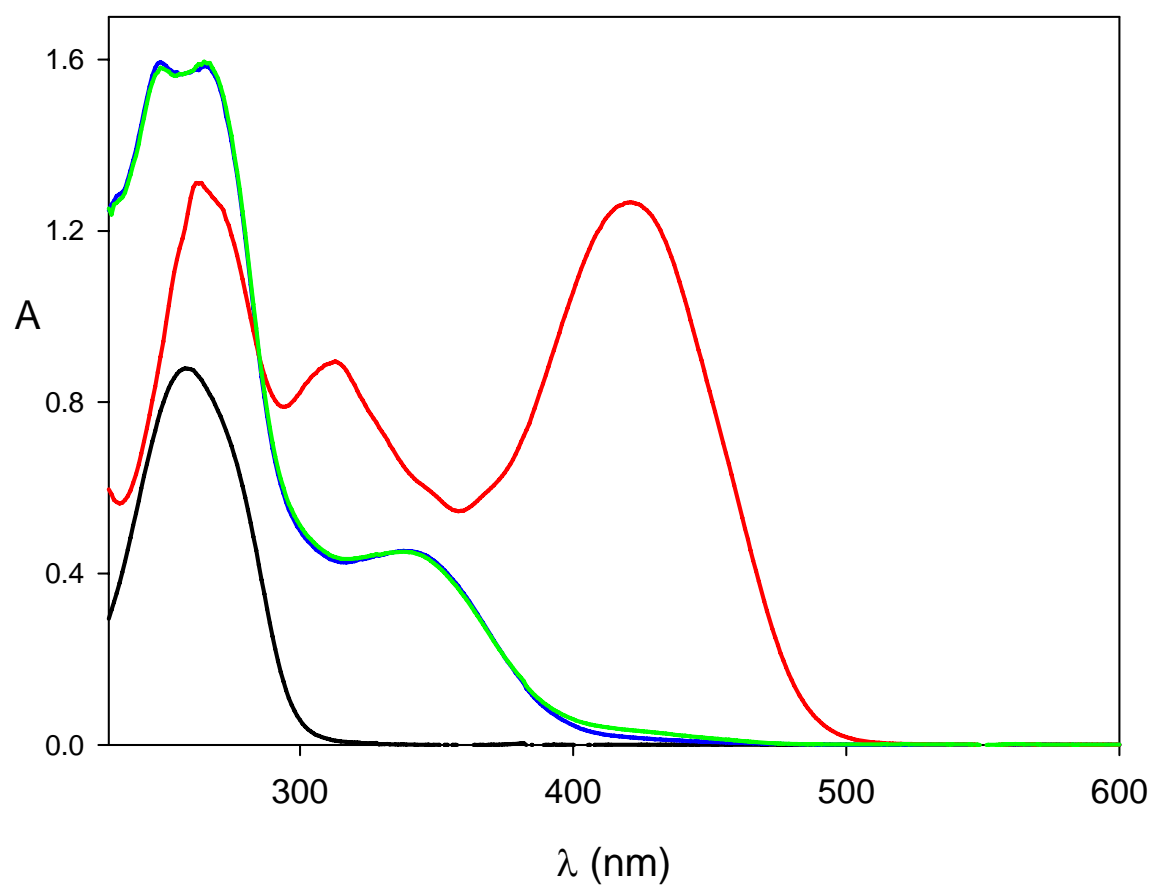

Figure S5. Absorption spectra in $\mathrm{CH}_{2} \mathrm{Cl}_{2}$ at room temperature of (i) $\mathbf{A H}^{2+}$, black curve; (ii) $\mathbf{A H}{ }^{2+}$ and $\mathbf{S P}$, immediately after the addition of the latter, blue curve; (iii) solution (ii) after 7 days of rest in the dark, red curve; (iv) solution (iii) after 9 minutes of irradiation at $\lambda>450 \mathrm{~nm}$, green curve. The concentration of all the components was $4.8 \times 10^{-5} \mathrm{M}$. 


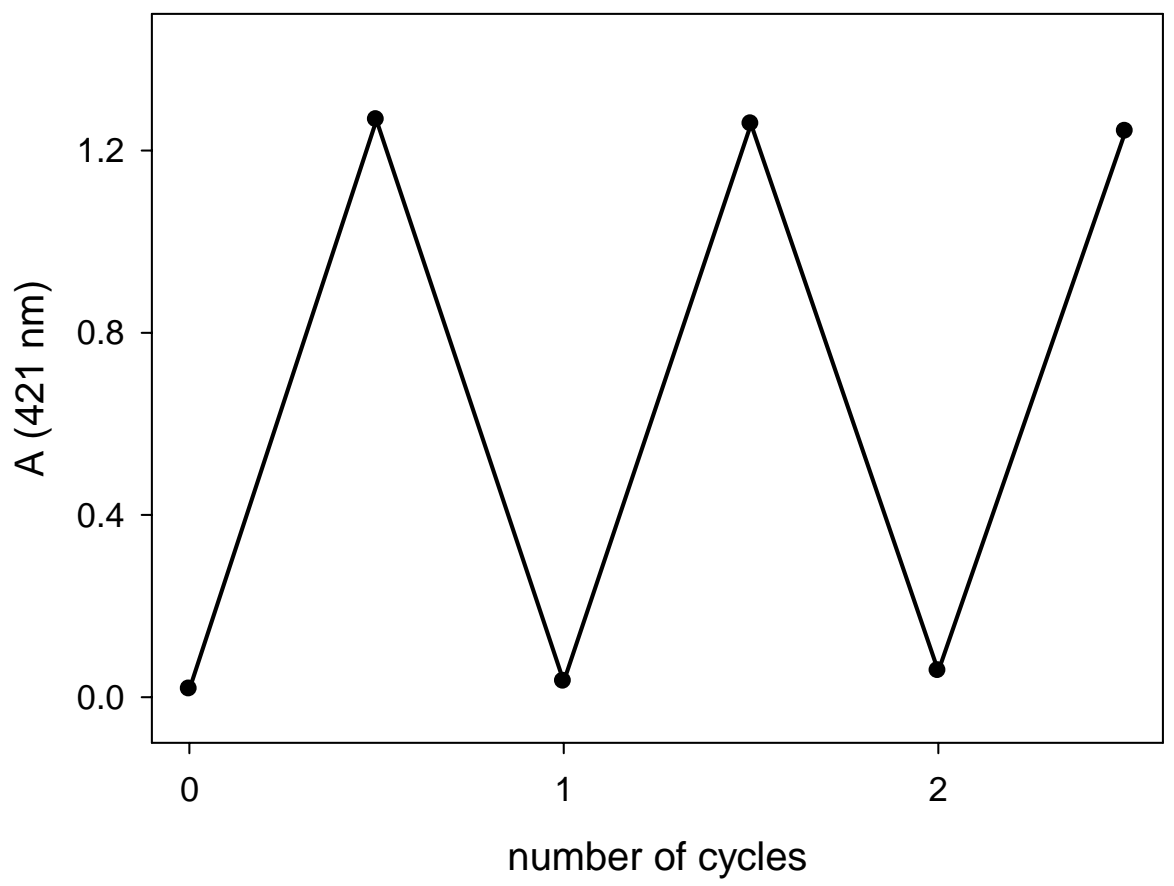

Figure S6. Absorption spectral changes at $421 \mathrm{~nm}$ of a $\mathrm{CH}_{2} \mathrm{Cl}_{2}$ solution containing $\mathbf{A H}^{2+}$ and $\mathbf{S P}\left(\right.$ all $\left.4.8 \times 10^{-5} \mathrm{M}\right)$ observed upon several cycles of thermal equilibration (7 days in the dark at room temperature) and visible light irradiation (10 minutes with a $150-\mathrm{W}$ tungsten-halogen lamp, $\lambda>450 \mathrm{~nm}$ ).

Re-equilibration of the SP- $\mathrm{AH}^{2+}$ system in the presence of $\mathrm{C}$. It is worthwhile noticing that the equilibrium state reached by thermal equilibration of $\mathbf{S P}$ with 1 equiv of $\mathbf{A} \mathbf{H}^{2+}$ contains a SP: $\mathbf{M E H}^{+}$ratio of 10:90, whereas the SP: $\mathbf{M E H}^{+}$ratio is $60: 40$ if SP equilibrates with the $[\mathbf{C} \cdot \mathbf{A H}]^{2+}$ complex. It can be expected that the apparent acid strength of the protonated axle $\mathbf{A H}^{2+}$ be smaller in the presence of the calixarene wheel for a thermodynamic reason, tha is, because deprotonation of the (threaded) axle must include the energetic price for the disassembly of the supramolecular complex. Such a behavior has indeed been observed in related compounds. ${ }^{\mathrm{S} 6}$ Moreover, it is known that the SP-MEH ${ }^{+}$equilibrium is strongly dependent on the medium (solvent, $\mathrm{pH}$, etc.). ${ }^{\mathrm{S} 7}$ It should be not very surprising, therefore, that the relative amounts of SP 
and $\mathbf{M E H}^{+}$in equilibrium with each other and with the $\mathbf{A H}^{2+}-\mathbf{A}^{+}$pair are different with and without the presence of wheel C. In fact, the larger SP: $\mathbf{M E H}^{+}$ratio observed in the presence of $\mathbf{C}$ is in agreement with the fact that the $\mathrm{AH}^{2+}$ axle is less prone to release a proton when it is threaded into $\mathbf{C}$.

In order to check whether these observations are related to the different thermodynamics of the switching ensemble in the absence and in the presence of the supramolecular complex, we performed the following experiment. A dichloromethane solution containing $\mathbf{A} \mathrm{H}^{2+}$ and $\mathbf{S P}$, both $4.8 \times 10^{-5} \mathrm{M}$, was prepared and left in the dark for equilibration. As previously observed, a proton exchange from $\mathbf{A H}^{2+}$ to SP takes place, and after 7 days about $90 \%$ of $\mathbf{S P}$ has been converted to $\mathbf{M E H}^{+}$(Figure S7). At this point, 1 equiv of calixarene $\mathbf{C}$ was added to the solution. An absorption band with $\lambda_{\max }=565 \mathrm{~nm}$ is observed immediately after the addition, together with a modest (13\%) decrease of the $\mathbf{A H}^{2+}$ band at $417 \mathrm{~nm}$ (Figure S7). The band peaking at $565 \mathrm{~nm}$, which is different from the CT band typical of the $[\mathbf{C} \cdot \mathbf{A H}]^{2+}$ complex $\left(\lambda_{\max }=478 \mathrm{~nm}\right)$, is ascribed to the formation of a small amount $\left(<8 \times 10^{-7} \mathrm{M}\right)$ of non-protonated merocyanine (ME). ${ }^{\text {S2,S7 }}$ It is likely that in the presence of $\mathbf{C}$ the highly favored self-assembly of the $[\mathbf{C} \cdot \mathbf{A H}]^{2+}$ pseudorotaxane drives the formation of some $\mathrm{AH}^{2+}$, thereby causing the deprotonation of a fraction of the $\mathbf{M E H}^{+}$species to $\mathbf{M E}$. The latter species is then slowly converted to SP, as shown by the almost complete disappearance of the absorption band at $570 \mathrm{~nm}$ over time. After $22 \mathrm{~h}$ in the dark at room temperature the absorption spectral changes are over, indicating that a new equilibrium state has been reached (Figure S7). Analysis of 417-nm band shows that the solution is characterized by a SP: $\mathbf{M E H}{ }^{+}$ratio of $58: 42$, i.e., identical within experimental error to that observed when SP equilibrates with 1 equiv of the $[\mathbf{C} \cdot \mathbf{A H}]^{2+}$ complex. The absorption in the 
500-600-nm region also becomes identical to that measured when SP equilibrates with 1 equiv of the $[\mathbf{C} \cdot \mathbf{A H}]^{2+}$ complex.

In summary, the same final state is reached by (i) thermal equilibration of $\mathbf{S P}, \mathbf{A H}^{2+}$ and $\mathbf{C}$ in a 1:1:1 ratio (see main text), and (ii) first thermal equilibration of $\mathbf{S P}$ and $\mathbf{A} \mathbf{H}^{2+}$ in a 1:1 ratio and subsequent re-equilibration caused by the addition of 1 equiv of the calixarene wheel $\mathbf{C}$. These observations indicate clearly that the different $\mathbf{S P}: \mathbf{M E H}^{+}$ratio observed in the presence of either $\mathbf{A} \mathbf{H}^{2+}$ or $[\mathbf{C} \cdot \mathbf{A H}]^{2+}$ is related to thermodynamic reasons.

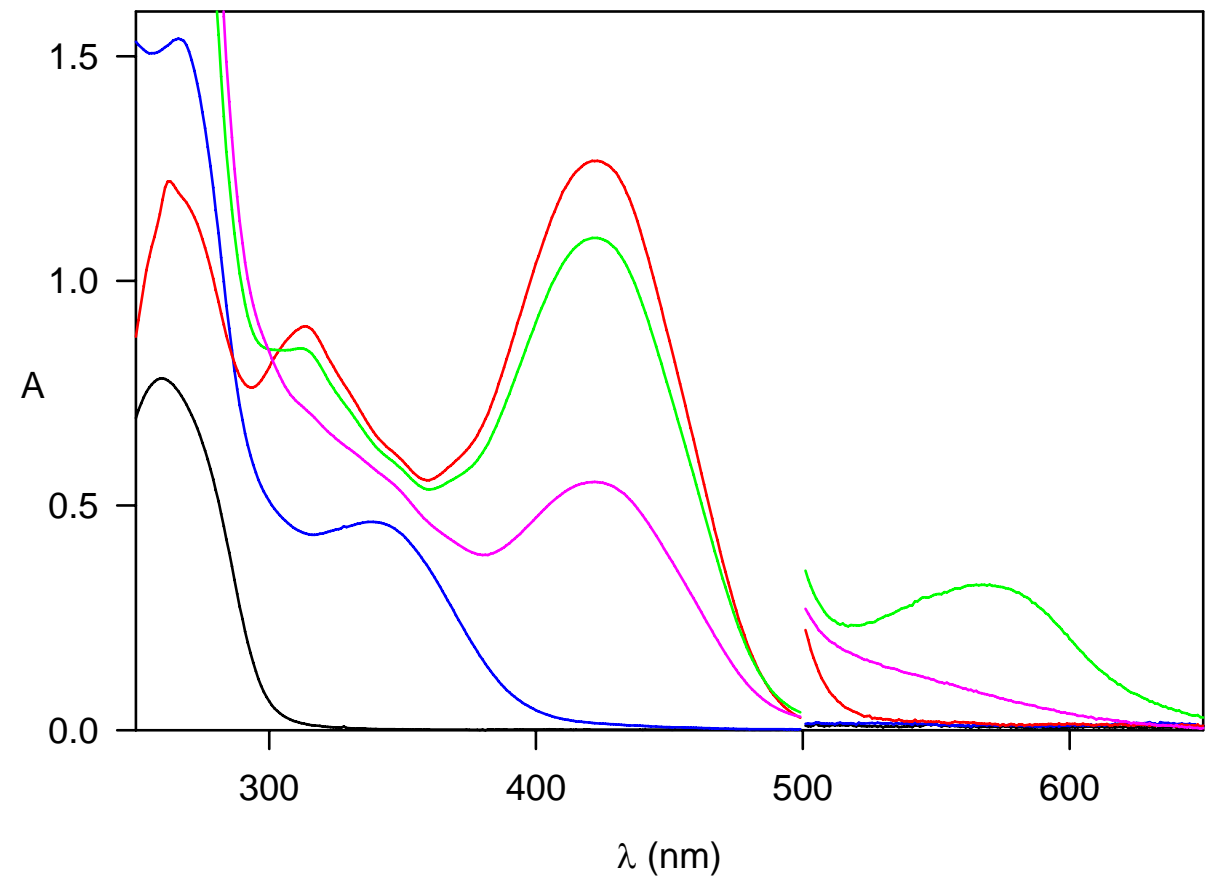

Figure S7. Absorption spectra in $\mathrm{CH}_{2} \mathrm{Cl}_{2}$ at room temperature of (i) $4.8 \times 10^{-5} \mathrm{M} \mathrm{AH}^{2+}$, black curve; (ii) solution (i) immediately after the addition of 1 equiv of SP, blue curve; (iii) solution (ii) after 7 days of rest in the dark, red curve; (iv) solution (iii) immediately after the addition of 1 equiv of calixarene $\mathbf{C}$, green curve; (v) solution (iv) after $22 \mathrm{~h}$ of rest in the dark, pink curve. 


\section{References}

S1. Alvarado, R. J.; Mukherjee, J.; Pacsial, E. J.; Alexander, D.; Raymo, F. M. J. Phys. Chem. B 2005, 109, 6164-6173.

S2. (a) Raymo, F. M.; Giordani, S. J. Am. Chem. Soc. 2001, 123, 4651-4652. (b) Raymo, F. M.; Giordani, S.; White, A. J. P.; Williams, D. J. J. Org. Chem. 2003, 68, 4158-4169.

S3. González, J. J.; Ferdani, R.; Albertini, E.; Blasco, J. M.; Arduini, A.; Pochini, A.; Prados, P.; de Mendoza, J. Chem. Eur. J. 2000, 6, 73-80.

S4. $\quad$ Binstead, R.A. SPECFIT; Spectrum Software Associates, Chapel Hill: NC, 1996.

S5. Credi, A.; Dumas, S.; Silvi, S.; Venturi, M.; Arduini, A.; Pochini, A.; Secchi, A. J. Org. Chem. 2004, 69, 5881-5887.

S6. Balzani, V.; Clemente-Leon, M.; Credi, A.; Lowe, J.N.; Badjic, J.D.; Stoddart, J.F.; Williams, D.J. Chem. Eur. J. 2003, 9, 5348-5360. (b) Badjic, J.D.; Balzani, V.; Credi, A.; Lowe, J.N.; Silvi, S.; Stoddart J.F. Chem. Eur. J. 2004, 10, 1926-1935. (c) Badjic, J.D.; Ronconi, C.M.; Stoddart, J.F.; Balzani, V.; Silvi, S.; Credi, A. J. Am. Chem. Soc. 2006, 128, 1489-1499.

S7. Wojtyk, J. T. C.; Wasey, A.; Xiao, N.-N.; Kazmaier, P. M.; Hoz, S.; Yu, C.; Lemieux, R. P.; Buncel, E. J. Phys. Chem. A 2007, 111, 2511-2516. 